\title{
OS USOS DO TERRITÓRIO E A GESTÃO DE ÁREAS PROTEGIDAS: O CASO DA APA CARAÍVA TRANCOSO (PORTO SEGURO, BA)
}

\author{
Raíssa Tamassia Côrtes ${ }^{1}$ \\ Fernando Souza Damasco ${ }^{2}$
}

\section{RESUMO}

Diante dos acordos internacionais de comprometimento com a conservação da biodiversidade, o governo brasileiro institui o Sistema Nacional de Unidades de Conservação (SNUC), pela Lei Federal $\mathrm{n}^{\circ}$ 9.985/2000, como uma de suas principais estratégias de ordenamento territorial com vistas a conservação de áreas naturais remanescentes. Essa política pública prevê a participação da comunidade no processo de gestão das áreas protegidas. Porém, frente à ineficiência de seus instrumentos, a consideração do território efetivamente usado pelas comunidades dentro de unidades de conservação pode trazer subsídios para sua devida implementação. O presente trabalho apresenta uma metodologia de mapeamento dos usos do território dentro de uma unidade de conservação de uso sustentável, a Área de Proteção Ambiental Caraíva Trancoso (Porto Seguro, BA). A proposta considera a caracterização da estrutura territorial da unidade, a identificação e classificação dos agentes territoriais, para, por fim, espacializar os usos do território. Além da distribuição geográfica dos tipos de uso e cobertura, o estudo dos usos territoriais permitiu entender como os diferentes sujeitos sociais usam o seu território, como se relacionam com ele e entre si, e de que forma isso reflete no ambiente em que vivem. Essa perspectiva analítica demonstrou ser um instrumento potencial para a gestão de áreas protegidas que seja verdadeiramente comprometida com os usos tradicionais e com os pressupostos de consulta e participação das comunidades.

Palavras-chave: Usos do território; gestão de áreas protegidas; unidades de conservação.

\section{TERRITORIAL USES AND PROTECTED AREA MANAGEMENT: THE CASE OF APA CARAÍVA TRANCOSO (PORTO SEGURO, BA)}

\begin{abstract}
Facing international agreements to commit to biodiversity conservation, the Brazilian government institutes the National System of Conservation Units, regulated by federal law $\mathrm{n}$. $9.985 / 2000$, as the main strategy of territorial planning for conserving natural areas. Although this policy brings instruments to provide community participation in protected area management, their inefficiency indicates that analyzes that consider territorial concepts and community uses in the conservation unit should be more effective to ensure its implementation. This study introduces a mapping methodology of territorial uses in the Environmental Protection Area Caraíva Trancoso (Porto Seguro, BA). The conservation unit

\footnotetext{
${ }^{1}$ Engenheira Florestal, Mestre em Práticas em Desenvolvimento Sustentável pela UFRRJ, acadêmica do curso de Especialização em Análise Ambiental e Gestão do Território da Escola Nacional de Ciências Estatísticas (ENCE/IBGE). E-mail: raissa.cortes@gmail.com

${ }^{2}$ Geógrafo, Mestre em Geografia pela UFF, docente do curso de Especialização em Análise Ambiental e Gestão do Território da Escola Nacional de Ciências Estatísticas (ENCE/IBGE). E-mail: fernandodamasco@id.uff.br
} 
territorial structure was characterized, then identify and classify territorial agents, for spatialize territorial uses. Beyond the geographic distribution of types of uses and coverture, the study of the uses of territorial enable the understanding how the social agents relation to themselves, to the territory they produce and live, and how it changes their environment. This analytic perspective showed a potential tool for protected area management and comprehension.

Keywords: Territorial uses; protected area management; protected area.

\section{INTRODUÇÃO}

A perda de diversidade biológica em várias partes do mundo trouxe ao debate o modelo político-econômico baseado no desenvolvimento econômico e sua dificuldade de conciliação com a conservação da natureza. Assim, durante a ECO-92, foi estabelecida a Convenção sobre Diversidade Biológica, que tem dentre seus principais objetivos a conservação da biodiversidade e a utilização sustentável de seus componentes, de forma a compatibilizar proteção de recursos naturais e desenvolvimento econômico e social (MMA, 2000, p. 9). No Brasil, foi ratificada pelo Decreto Federal no 2.519, de 16 de março de 1998 e, procurando cumprir os compromissos internacionais assumidos, em 2000 o governo brasileiro institui o Sistema Nacional de Unidades de Conservação (SNUC), pela Lei Federal nº 9.985/2000.

O SNUC define como Unidade de Conservação (UC) o "espaço territorial e seus recursos ambientais, incluindo as águas jurisdicionais, com características naturais relevantes, legalmente instituído pelo Poder Público, com objetivos de conservação e limites definidos, sob regime especial de administração, ao qual se aplicam garantias adequadas de proteção" (BRASIL, 2000, s/p.).

Essa lei altera a concepção e o procedimento de criação e gestão de UC no país e conta com instrumentos que consideram a participação da comunidade no processo de gestão dessas áreas protegidas, bem como prevê a possibilidade de uso sustentável dos recursos naturais em parte das unidades categorizadas. Entretanto, são muitos os casos em que, apesar de passados 19 anos da promulgação da lei do SNUC, os objetivos de participação popular não são alcançados. A ineficiência de seus instrumentos ainda confirma que a questão da territorialidade e da formação sócio espacial brasileira é desconsiderada na construção dessas políticas públicas (SOUZA, 1998, p. 25).

O SNUC representa um novo elemento na política ambiental brasileira buscando reunir o ordenamento do território a ser protegido junto com os objetivos de conservação. Porém, é preciso compreender que as UC não são apenas espaços delimitados que materializam definições sobre conservação da natureza. Elas também são territórios produzidos por diferentes práticas sociais, mediadas por relações de poder e concretizadas pela via do controle territorial (COELHO et al., 2009).

Assim, questiona-se como devem ser estudadas as UC de modo a contemplar o conteúdo dessas relações. Na tentativa de superar o tradicional levantamento de uso e ocupação da terra, estudos que evidenciem a territorialidade dos tipos de uso nessas áreas 
protegidas, numa análise que considere também as relações territoriais, são cada vez mais importantes.

Milton Santos (1998, p. 16) nos traz que "o território são formas, mas o território usado são objetos e ações, sinônimo de espaço humano, espaço habitado". O uso do território é a categoria de análise que busca relacionar a materialidade com um sistema de ações e intenções, bem como as normas que regulam e atuam no território usado pelo homem (SANTOS \& SILVEIRA, 2006, p. 21).

O presente trabalho procurou identificar os usos do território dentro de uma UC de uso sustentável, considerando as múltiplas relações territoriais e como elas influenciam na gestão de áreas protegidas, lançando bases iniciais para o desenvolvimento de procedimentos metodológicos em torno da identificação e mapeamento de usos do território.

\section{PROCEDIMENTOS METODOLÓGICOS}

\section{Área de Estudo}

A Área de Proteção Ambiental (APA) Caraíva Trancoso é uma UC de domínio estadual, tendo como órgão gestor o Instituto do Meio Ambiente e Recursos Hídricos do Estado da Bahia (INEMA). A unidade se localiza na extremidade sul do município de Porto Seguro (BA), em sua porção litorânea. Possuindo 31.900 hectares, a APA se sobrepõe a duas Terras Indígenas (TI) e outras três UC Federais (Figura 1). Aproximadamente 30\% da área total do Município de Porto Seguro (BA) encontra-se protegida por UC, sendo que 42.300 hectares estão em unidades de Proteção Integral (17\%) e 44.200 hectares em áreas de Uso Sustentável (13\%). Além disso, o município ainda possui quatro Terras Indígenas em seu território, sendo três delas já homologadas: Coroa Vermelha, Imbiriba e Barra Velha.

O município de Porto Seguro, em 1970 contava com 11\% de população urbana. Este contingente chegou a 67\% em 1991 (IBGE, 1970, 1980, 1991, 2000, 2010), fortemente influenciado pela crise da cultura do cacau na região de Ilhéus e Itabuna, que liberou enormes contingentes de mão-de-obra, e pelo maciço investimento no turismo no município de Porto Seguro, realizado pelos governos federal e estadual (CARVALHO, 2008).

\section{Levantamento Documental}

Foi necessário compreender o histórico da APA Caraíva Trancoso para identificar os principais agentes que influenciam os usos do território e suas mudanças. Para tanto, além do levantamento bibliográfico, foram analisados os documentos relativos à criação e a gestão da UC. 
Figura 1 - Localização da APA Caraíva Trancoso e outras áreas protegidas no Município de Porto Seguro (BA).

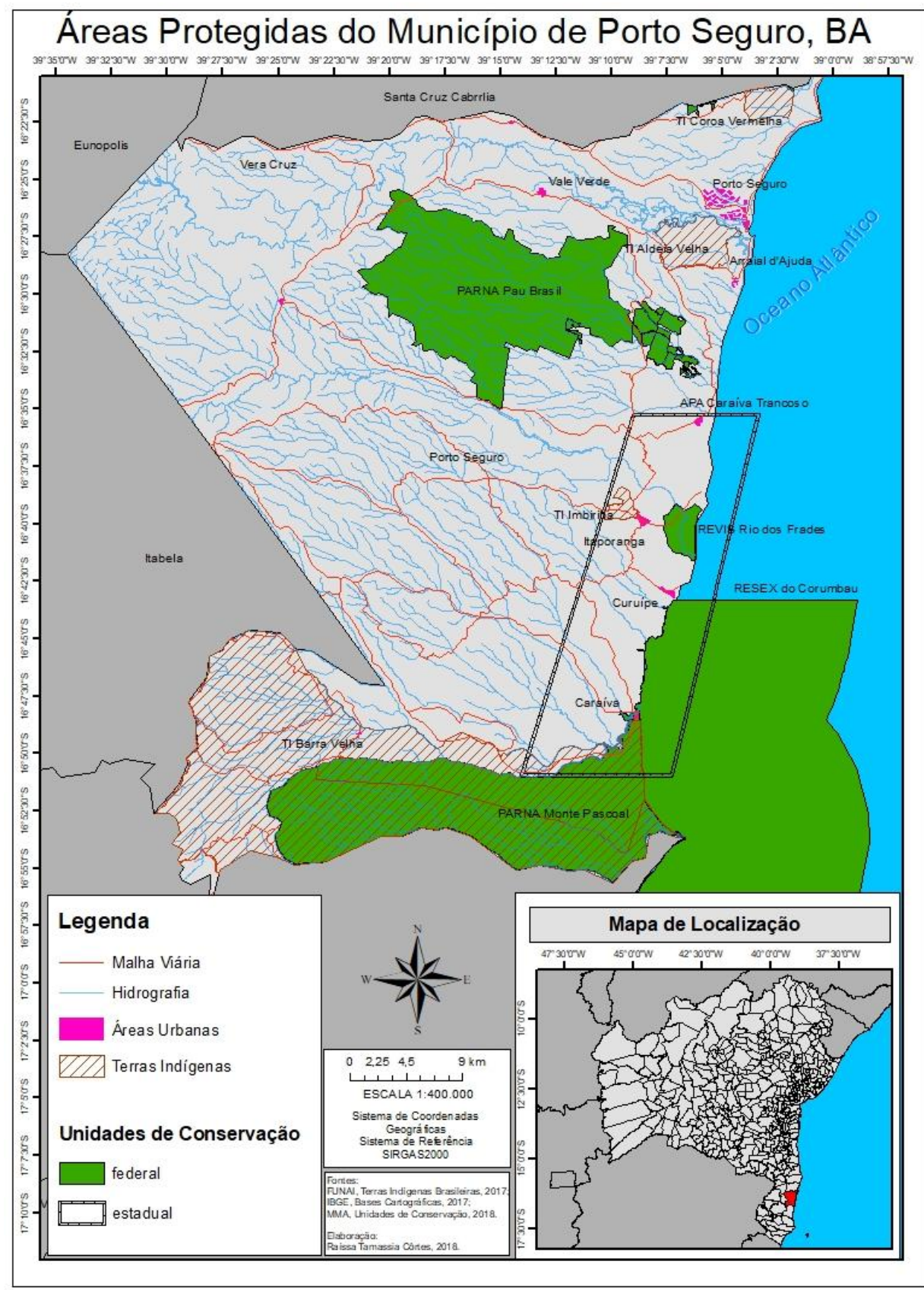

Elaboração: Raíssa Côrtes, 2018.

\section{Identificação e Mapeamento dos Usos do Território}

Após a identificação dos principais agentes, foram pontuados nove parâmetros de avaliação a serem coletados, com o objetivo de reconhecer os usos realizados por cada um deles e como se dá sua relação com o território: (1) vínculo com o território; (2) principais usos realizados; (3) usos restringidos; (4) usos da vegetação; (5) abrangência de uso; (6) 
regularidade de uso; (7) contra/a favor da APA; (8) beneficiado ou afetado pela APA; e (9) relação com o território (conflituosa, dependência ou convivência).

Uma matriz foi organizada de forma que fosse possível, durante as visitas de campo, preenchê-la com as observações obtidas para posterior avaliação. Foram realizadas entrevistas semiestruturadas com um total de 11 pessoas dentre os diferentes grupos pesquisados. Devido ao tempo limitado da pesquisa não foi possível conversar com um representante de cada agente territorial identificado, privilegiando-se os agentes pertencentes à comunidade local, os órgãos gestores e a sociedade civil organizada. Para esses três grandes grupos foram elaborados questionários específicos.

As visitas a campo, para além das entrevistas realizadas, percorreram a área da APA através da estrada principal que liga seus dois principais distritos, de Trancoso a Caraíva. Foram visitados 22 pontos dentro da UC procurando-se verificar os tipos de usos realizados no território da APA (Figura 2), sendo observados: (1) as principais atividades econômicas realizadas; (2) as principais ocupações dos moradores da APA; (3) os principais fluxos de pessoas dentro da APA; (4) áreas centrais de gestão do território e mobilização social que influenciam nas atividades realizadas dentro da UC; e (5) áreas identificadas com conflitos de uso.

As percepções obtidas, tanto nas visitas a campo quanto através das entrevistas, foram compiladas com o objetivo de identificar, localizar e compreender os usos do território. Foi possível realizar o mapeamento dos usos do território a partir da coleta de pontos de GPS que permitiram a espacialização dessas informações.

O mapeamento procurou delimitar também: (1) zonas de fronteira de usos: onde o avanço de um uso implica em impacto a outro uso; (2) zonas de conflito de uso: locais onde se sobrepõe mais de um uso; e (3) os fluxos identificados no território: movimentos realizados pelos moradores da APA. Para possibilitar o mapeamento dos usos do território foi necessário, inicialmente, caracterizar a configuração da estrutura territorial dentro da APA Caraíva Trancoso. Ao identificar os agentes territoriais que compõe essa estrutura, e compreender como eles ocupam e usam o território da APA, foi possível delimitar os usos territoriais.

\section{ESTRUTURA TERRITORIAL NA APA CARAÍVA TRANCOSO}

Na APA Caraíva Trancoso a maior parte das atividades se concentra em torno dos núcleos populacionais, principalmente nas sedes distritais. A UC criada em 1993, possui plano de manejo datado de 1998 e zoneamento aprovado no ano 2000. Esses documentos destacam a importância da unidade para o turismo da região, tendo como principal objetivo o ordenamento da área delimitada entre os povoados de Caraíva e Trancoso para o estabelecimento de um turismo planejado e de baixa densidade (URPLAN, 1998). Seu conselho gestor esteve ativo entre os anos de 2005 e 2014, estando atualmente desmobilizado. A APA não possui sede física, veículos ou pessoal empregado diretamente para sua gestão. 
Figura 2 - Pontos visitados para coleta de dados na APA Caraíva Trancoso.

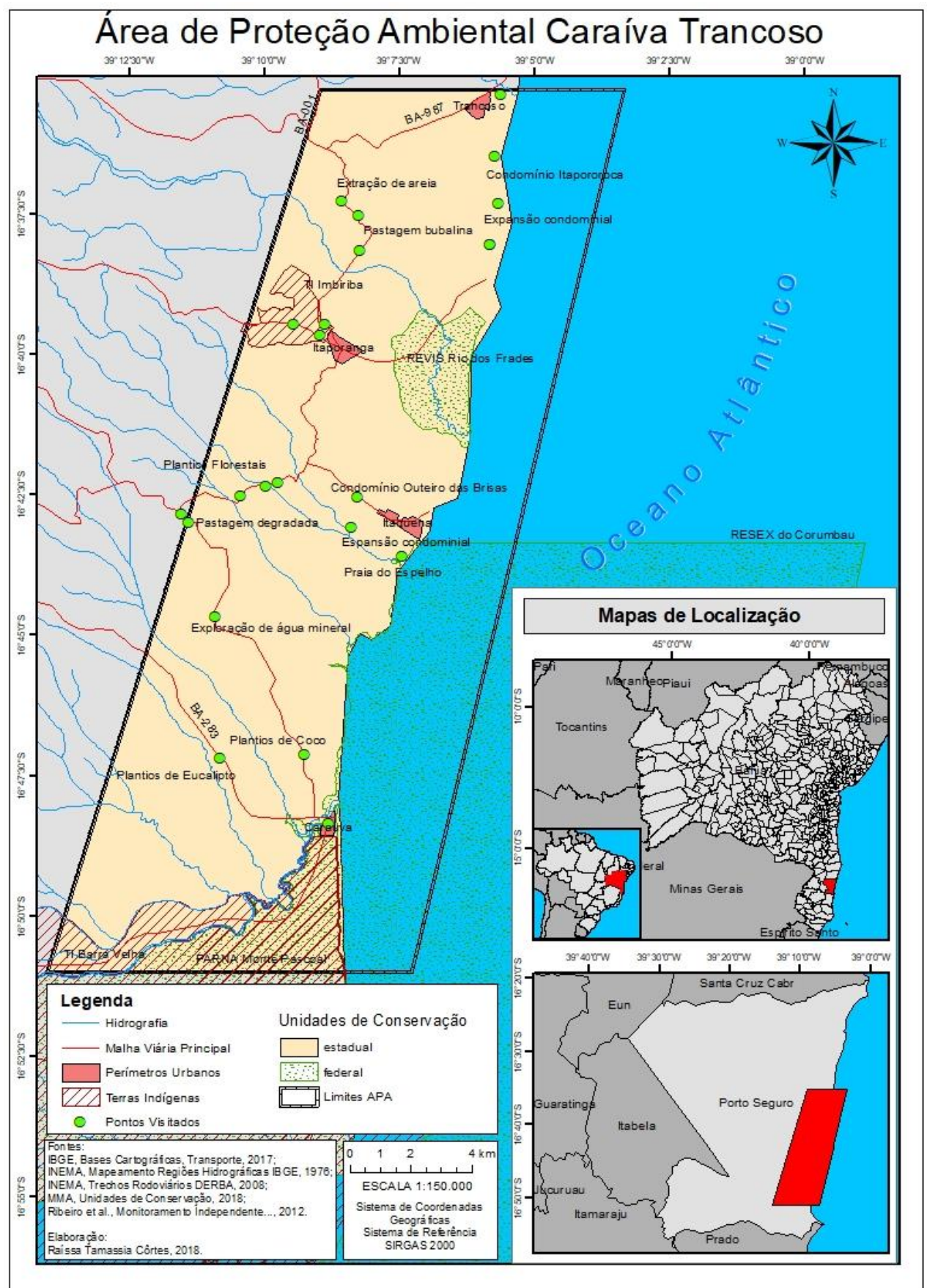

Trancoso tem seus casarios históricos do século VII ocupados por restaurantes refinados e lojas de grife, caracterizando um turismo de luxo. A localidade apresenta grande quantidade de casas de veraneio, organizadas em terrenos independentes e em áreas condominiais, sendo identificados grandes empreendimentos com infraestrutura robusta nas áreas de praia. Na sede do distrito há grande número de agências imobiliárias e lojas de materiais de construção, indicando intensa expansão imobiliária. 
A vila de Caraíva se localiza entre o rio Caraíva e o Parque Nacional e Histórico do Monte Pascoal, que se sobrepõe a Terra Indígena de Barra Velha. Apesar da grande influência do turismo, não há possibilidades de expansão imobiliária. Nas áreas próximas à praia espalham-se pequenos restaurantes, pousadas e barracas de praia, atraindo investidores de fora da localidade. Na margem oposta do rio organiza-se Nova Caraíva, onde existe recente expansão imobiliária no formato de loteamentos e empreendimentos turísticos de pequeno porte.

Sendo o turismo a principal atividade e fonte de renda na região, as praias também movimentam grande fluxo temporário de pessoas, tanto de moradores quanto de visitantes, e apresentam estruturas específicas para atendimento aos turistas. Destaca-se a Praia do Espelho, na localidade de Curuípe, que apresenta uma estrutura consolidada de turismo de praia, bem como área condominial de alto luxo.

Ainda, pontua-se a existência (resistência) da vila de Itaporanga e da Terra Indígena de Imbiriba. Localizada entre as duas sedes distritais, a grande maioria dos moradores, tanto da vila quanto da aldeia, trabalham com atividades ligadas ao turismo: os moradores vendem passeios, alugam suas casas para turistas na alta temporada, possuem serviço de táxi, fazem artesanatos, ou ainda trabalham na colheita das grandes propriedades na baixa temporada, enquanto aguardam os empregos temporários em hotéis, condomínios e barracas de praia, principalmente na localidade de Curuípe.

Entre os núcleos populacionais e as praias estruturadas, existem áreas consideradas intermediárias, ocupadas por atividades agrícolas, destacando-se as pastagens e monoculturas florestais, ou remanescentes de vegetação nativa.

\section{OS AGENTES DO TERRITÓRIO E SEUS USOS}

A identificação dos agentes territoriais possibilitou classificá-los em quatro grandes grupos: (1) agentes originários ou tradicionais: comunidades indígenas e pescadores artesanais, cuja relação com o território é de dependência; (2) agentes de exploração comunitária ou familiar: pequenos comerciantes, artesãos, trabalhadores rurais e agricultores familiares, que têm no território sua moradia, seu trabalho e sua recreação; (3) agentes de uso ocasional ou temporário: neste grupo estão incluídos os turistas e moradores de veraneio, são os agentes que mais movimentam pessoas e geram renda na APA; e (4) agentes relacionados à exploração ou dominação territorial: caracterizados pelos latifundiários e grandes empreendimentos turísticos e suas áreas de expansão, localizados nas áreas urbanas ou nas áreas rurais.

A partir da estrutura territorial identificada e da área de abrangência de cada um dos agentes classificados, foram definidas 18 classes de uso que buscaram caracterizar a dinâmica de uso no território em estudo. A definição dessas classes considerou, além dos usos apontados pelos atores, as áreas de usos restringidos pela legislação através das UC de proteção integral, visto que essa restrição e sua sobreposição com outros usos geram conflitos territoriais. Os plantios de coco foram extremamente atrativos para a mão-de-obra e a 
ocupação da APA no passado, constituindo as vilas de Itaporanga e Nova Caraíva. Já as áreas de pastagem bubalina apresentam conflitos com usos tradicionais e, portanto, essas classes de uso econômico foram diferenciadas das demais. Ainda, foram identificados os fluxos de pessoas dentro da APA Caraíva Trancoso (Tabela 1 e Figura 3).

Tabela 1 - Tipos de uso e classes definidas para os usos do território na APA Caraíva Trancoso.

TIPOS DE USO

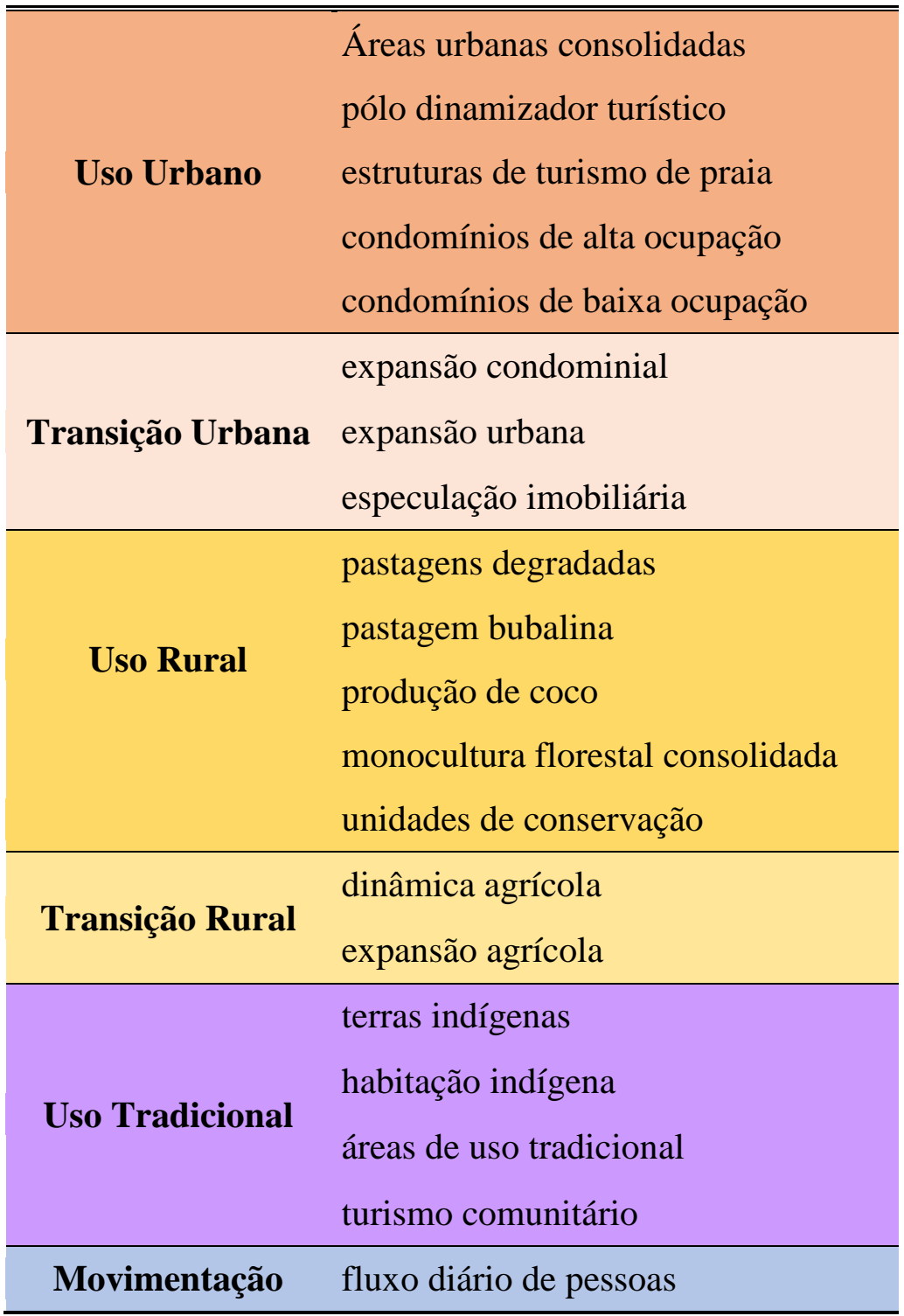


Figura 3 - Mapa dos usos territoriais na APA Caraíva Trancoso.

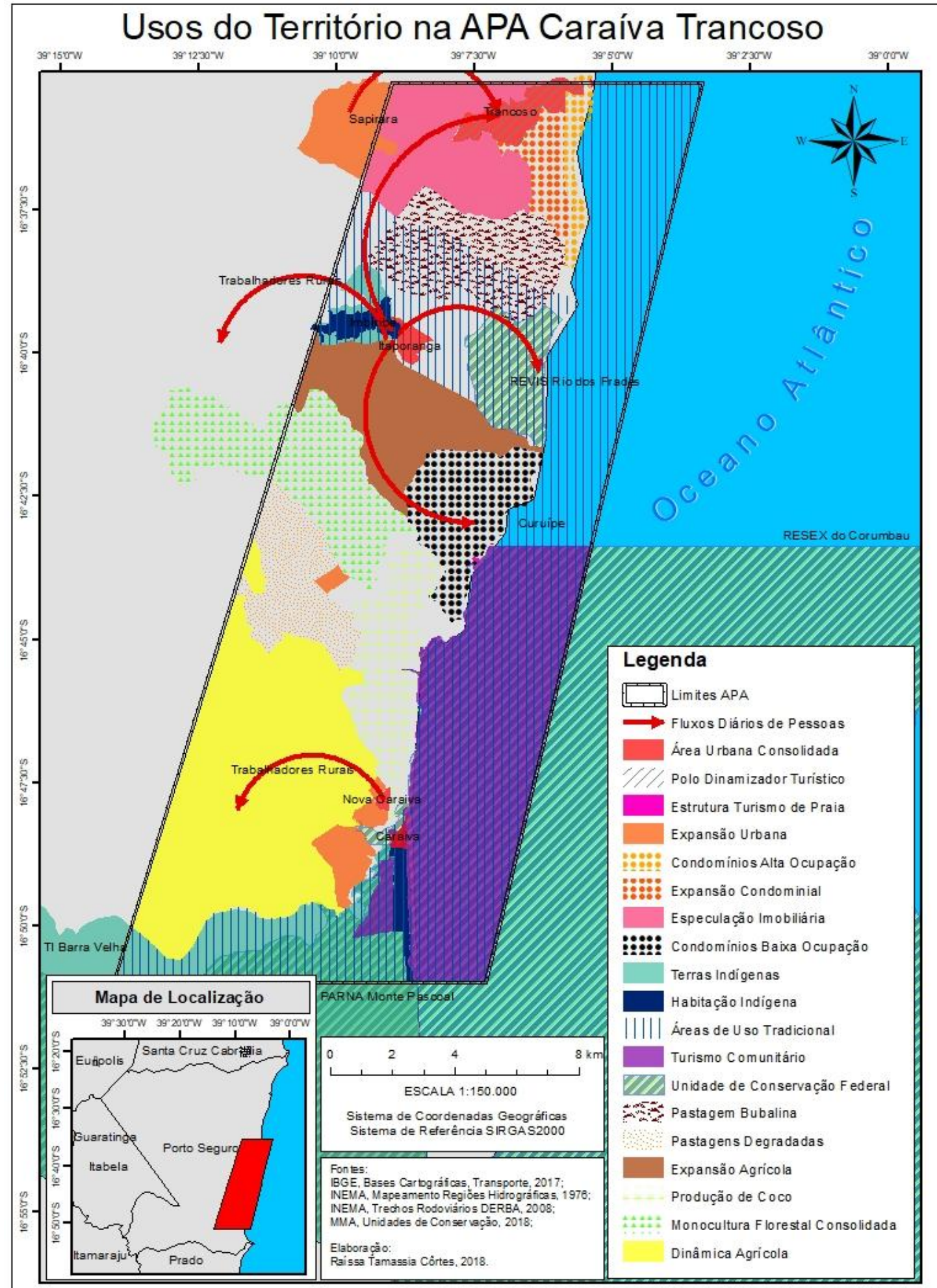


As localidades de Trancoso, Itaporanga, Nova Caraíva e Caraíva foram classificadas como áreas urbanas consolidadas ${ }^{3}$ e apresentam eletricidade, escolas, posto de saúde, posto policial e coleta de lixo. Dentre elas, Trancoso se destaca como polo dinamizador turístico da região, não apenas por concentrar grande parte das atividades relacionadas ao turismo, mas também por dinamizar essas atividades na região apresentando grande movimentação de pessoas entre Trancoso e as outras localidades. Ao seu redor se organizam duas frentes de expansão: (1) expansão urbana para fins de moradia, e (2) expansão condominial de luxo com principal finalidade de veraneio. Associada às áreas de expansão de Trancoso, que fazem limites com áreas rurais, foi possível identificar uma grande área de especulação imobiliária sobre grande fragmento remanescente de áreas naturais da APA que ainda encontra-se em bom estado de conservação. A área encontra-se em perigo de degradação ambiental frente à expansão urbana e rural. Na localidade de Nova Caraíva também foi identificada área de expansão urbana para fins de moradia.

Estruturas massivas de turismo de praia foram encontradas em Trancoso e Curuípe/Praia do Espelho. No litoral sul de Trancoso foram identificados condomínios e resorts de alta ocupação, caracterizados por áreas densamente ocupadas e diretamente ligadas ao polo dinamizador turístico, com forte dinâmica de construção civil e supressão vegetal. Já na localidade de Curuípe/Praia do Espelho, encontram-se condomínios de baixa ocupação, compostos por áreas condominiais em grandes lotes, menor dinâmica de construção civil, porém, com potencial de atividade geradora de impactos ambientais pela supressão vegetal e a produção de lixo.

As pastagens encontradas na APA Caraíva Trancoso são, em sua maioria, extensivas, sem a devida proteção dos mananciais e com voçorocas e feições erosivas expostas. As áreas de monoculturas florestais, principalmente plantios de eucalipto, indicam a influência das empresas de celulose da região dentro da APA. Essas áreas foram destacadas, pois a atividade foi regulamentada pelo conselho gestor da unidade, que definiu que os plantios deveriam se manter a $10 \mathrm{~km}$ do litoral, para garantir o atrativo paisagístico da região. Outro ponto importante relacionado a regulação desta cultura é a concentração fundiária, o esvaziamento do campo e a diminuição da diversidade de produção agrícola ocorrida em outros municípios da região.

Diferentemente das áreas de transição urbano-rural, foram identificados na porção central da APA fragmentos de remanescentes naturais com incursão de atividades agrícolas, principalmente pastagens, plantios florestais e produção de coco próximo ao litoral, caracterizando uma frente de expansão agrícola. Dentre as classes de uso rurais, foi definida

\footnotetext{
${ }^{3}$ A discussão do conceito urbano-rural não é objetivo central do presente trabalho e, portanto, considerou-se a definição dos núcleos urbanos indicados no Plano Diretor Municipal Participativo de Porto Seguro (Lei Municipal no 38/2018).
}

ISSN 2318-2148 
área de dinâmica agropecuária, ocupada por diferentes culturas através do tempo: pastejo rotacionado ${ }^{4}$, cafeicultura e plantios florestais.

As áreas classificadas como de uso tradicional extrapolam o limite das terras indígenas homologadas. No caso de Imbiriba, os depoimentos coletados indicam o uso do vale do Rio dos Frades e das áreas de praia e mangue pelos indígenas. Dessa forma, as áreas de uso tradicional englobaram desde a TI de Imbiriba até as áreas do Refúgio de Vida Silvestre (REVIS) Rio dos Frades, cujo gestor também apontou o uso da UC por pescadores artesanais e marisqueiras, inclusive com a existência de um porto na área de praia. Importante destacar que o REVIS é uma unidade de proteção integral, sendo, portanto, mais restritiva que a APA. Porém, o REVIS prevê a existência de áreas particulares em seu interior, desde que suas atividades sejam compatíveis com os objetivos da unidade.

Ainda, a área mapeada de uso tradicional inclui as áreas marinhas da APA e se sobrepõe em parte com a Reserva Extrativista (RESEX) de Corumbau, UC de uso sustentável também utilizada por pescadores artesanais e indígenas.

Áreas de turismo comunitário foram identificadas na localidade de Caraíva, onde o turismo náutico na área da RESEX e a travessia do rio Caraíva são de responsabilidade dos pescadores artesanais, e os passeios de buggy são gerenciados pelos indígenas locais. Para o limite marinho do turismo de base comunitária ${ }^{5}$ considerou-se o limite norte da RESEX de Corumbau, em sobreposição a APA.

O mapeamento de todas as classes permitiu visualizar áreas de sobreposição de uso, bem como áreas de remanescentes naturais que sofrem pressão de frentes de expansão urbanas e rurais. A análise dos usos sobrepostos possibilita verificar onde sua coexistência ocorre de forma pacífica, exploratória ou conflituosa. A sobreposição entre os usos tradicionais e as áreas de pastagens indica que o uso realizado pelos indígenas vem sendo restringido por atividades hegemônicas ${ }^{6}$ dentro da APA, resultando em conflitos territoriais. As áreas de praia ocupadas pelos condomínios também restringem o acesso de pescadores às áreas litorâneas e seu uso tradicional. Os fluxos diários de pessoas mostram os deslocamentos que os trabalhadores da APA realizam para sobreviver, e permitem visualizar as relações exploratórias nas áreas rurais e relacionadas ao turismo. Poucas áreas de sobreposição entre uso tradicional e as UC de proteção integral, como é o caso da REVIS Rio dos Frades, apresentam ponto pacífico de coexistência.

\footnotetext{
${ }^{4}$ Pastejo rotacionado se refere a uma técnica de manejo de pastagens onde a área de pasto é subdivida em piquetes, submetidos a períodos alternados de pastejo e descanso, resultando em melhor aproveitamento da forragem produzida e permitindo maior taxa de lotação da pastagem.

${ }^{5} \mathrm{O}$ turismo de base comunitária tem como características: autogestão; associativismo e cooperativismo; democratização de oportunidades e benefícios; centralidade da colaboração, parceria e participação; valorização da cultura local e, principalmente, protagonismo das comunidades locais na gestão da atividade e/ou na oferta de bens e serviços turísticos, visando à apropriação por parte destas dos benefícios advindos do desenvolvimento da atividade turística, sendo o turismo uma atividade complementar às atividades tradicionais desenvolvidas pelas comunidades.

${ }^{6}$ Tem-se como atividades hegemônicas dentro da APA Caraíva Trancoso a agropecuária extensiva e o turismo de alto luxo, considerando a implantação de resorts e áreas condominiais de veraneio.
} 


\section{CONSIDERAÇÕES FINAIS}

O mapeamento dos usos do território foi capaz de apresentar usos não costumeiramente considerados e estudados em levantamentos de cobertura e uso da terra, trazendo para o foco da análise as relações territoriais. O exercício de mapeamento realizado pelo trabalho mostrou onde os diferentes usos se sobrepõem e, portanto, como se relacionam no território. Foram reveladas áreas de expansão de atividades, pressão sobre remanescentes naturais, e locais de remobilização e rearranjo das comunidades devido aos seus usos restringidos, informações que consideraram, para além da materialidade, as ações humanas e sua dinâmica dentro do território. As ações de quem vive e transforma o local onde vive, produzindo o seu território. Os resultados deste trabalho procuram trazer uma perspectiva analítica que considere efetivamente o território usado na gestão de áreas protegidas, de forma a ampliar o debate sobre o atual sistema de criação e gestão de UC. A metodologia aqui proposta pode ter significativa utilidade para subsidiar a tomada de decisão em áreas protegidas, além de constituir-se como importante instrumento de diagnóstico territorial para planos de manejo e outros instrumentos de planejamento ambiental.

\section{REFERÊNCIAS BIBLIOGRÁFICAS}

BRASIL. (1998) Decreto no 2.519 de 16 de março de 1998. Promulga a Convenção sobre Diversidade Biológica, assinada no Rio de Janeiro, em 05 de junho de 1992. Brasília.

BRASIL. (2000) Lei no 9.985 de 18 de julho de 2000. Institui o Sistema Nacional de Unidades de Conservação da Natureza - SNUC. Brasília.

MINISTÉRIO DO MEIO AMBIENTE - MMA (2000). A Convenção sobre Diversidade Biológica - CDB. Série Biodiversidade nº 2, Brasília: MMA.

CARVAlHO, C. R. (2008) Uma Abordagem Geográfica do Turismo em Porto Seguro. 2008. Dissertação (Mestrado em Geografia Física) - Universidade de São Paulo, São Paulo.

COELHO, M. C. N.; CUNHA, L. H.; MONTEIRO, M. de A. (2009) Unidades de Conservação: populações, recursos e territórios. Abordagens da geografia e da ecologia política. In: GUERRA, A. J. T.; COELHO, M. C. N. (org.) Unidades de Conservação: abordagens e características geográficas. Rio de Janeiro: Bertrand Brasil.

IBGE - INSTITUTO BRASILEIRO DE GEOGRAFIA E ESTATÍSTICA. Censos Demográficos, 1970, 1980, 1991, 2000, 2010. Tabela 202 - População residente, por sexo e situação do domicílio. Tabela 1383 - Taxa de alfabetização das pessoas de 10 anos ou mais de idade por sexo. Disponível em: < https://sidra.ibge.gov.br/tabela/202\#resultado>. Acessado em: 24 ago. 2019.

PORTO SEGURO (2018) Projeto de Lei nº 038 de 05 de dezembro de 2018. Que aprova o Plano Diretor Municipal Participativo de Porto Seguro. Porto Seguro: Câmara Municipal. 
SANTOS, M. (1998) O retorno do território. In: SANTOS, M.; SOUZA, M. A. A. de; SILVEIRA, M. L. (org.) Território: globalização e fragmentação. São Paulo: Editora Hucitec/ANPUR, p. 15-20.

SANTOS, M.; SILVEIRA, M. L. (2006) A questão: o uso do território. In: SANTOS, M.; SILVEIRA, M. L. O Brasil: território e sociedade no início do século XXI. $9^{a}$ ed. Rio de Janeiro: Record, p. 19-22.

SOUZA, M. A. A. de. (1998) Geografia de desigualdade: globalização e fragmentação. In: SANTOS, M.; SOUZA, M. A. A. de; SILVEIRA, M. L. (org.) Território: globalização e fragmentação. São Paulo: Editora Hucitec/ANPUR, p. 21-28.

URPLAN - GRUPO DE PLANEJAMENTO URBANISMO E ARQUITETURA LTDA. (1998) Plano de Manejo da Área de Proteção Ambiental de Caraíva Trancoso. Zoneamento e Plano de Gestão. Porto Seguro. 120 p. Disponível em: <http://www.inema.ba.gov.br/gestao-2/unidades-de-conservacao/apa/apacaraiva-trancoso/>. Acessado em: 06 fev. 2018. 